\title{
Visualization of the stem water content of two genera with secondary phloem produced by successive cambia through Magnetic Resonance Imaging (MRI)
}

\author{
Elisabeth M. R. Robert ${ }^{1,2}$, Nele Schmitz ${ }^{1,2}$, Paul Copini ${ }^{3}$, Edo Gerkema ${ }^{4}$, Frank J. Vergeldt ${ }^{4}$, \\ Carel W. Windt ${ }^{5}$, Hans Beeckman ${ }^{2}$, Nico Koedam ${ }^{1, \dagger}$ and Henk Van As ${ }^{3, \dagger}$ \\ ${ }^{1}$ Laboratory of Plant Biology and Nature Management (APNA), Vrije Universiteit Brussel, Pleinlaan 2, B-1050 \\ Brussels, Belgium; ${ }^{2}$ Laboratory of Wood Biology and Xylarium, Royal Museum for Central Africa (RMCA), \\ Leuvensesteenweg 13, B-3080 Tervuren, Belgium; ${ }^{3}$ Forest Ecology and Forest Management Group, Wageningen \\ University, P.O. Box 47, 6700 AA Wageningen, The Netherlands; ${ }^{4}$ Laboratory of Biophysics and Wageningen NMR \\ Centre, Wageningen University, Dreijenlaan 3, 6703 HA Wageningen, The Netherlands; ${ }^{5}$ Forschungszentrum Jülich, \\ Institute for Bio- and Geosciences, IBG-2: Plant Sciences, Leo Brandt street 1, 52425 Jülich, Germany.
}

Corresponding author: Elisabeth Robert, erobert@vub.ac.be

${ }^{\dagger}$ These authors supervised the work equally.

Date of submission: $6^{\text {th }}$ August 2014

\section{Abstract}

Shrubs and trees with secondary phloem tissue produced by successive cambia mainly occur in habitats characterized by a periodical or continuous lack of water availability. The amount of this secondary phloem tissue in stems of Avicennia trees rises with increasing soil water salinity and decreasing inundation frequency. Hence, increased water storage in secondary phloem tissue produced by successive cambia was put forward to be advantageous in harsh environmental conditions. It was however never tested whether the secondary phloem cells over the entire stem of woody species showing this wood anatomical feature are indeed water-filled as expected. In this preliminary and pioneering study, we use magnetic resonance imaging (MRI) to visualize the stem water content of three species with successive cambia, the mangroves Avicennia marina and $A$. officinalis and the non-mangrove Bougainvillea spectabilis. Measurements were conducted in living plants. We tested the hypothesis that not only the outermost phloem tissue has high water content but also the secondary phloem tissues over the entire stem from the bark inward to the pith, herewith serving as water storage sites. We can conclude that all secondary phloem tissue of both Bougainvillea and Avicennia has high water contents. This aligns with the contribution of secondary phloem tissue produced by successive cambia to ecological success in conditions of physiological drought. Further study should however be done to understand the mechanisms through which this secondary phloem tissue contributes to the water household of plants in conditions of water shortage.

\section{Introduction}

The secondary phloem tissue produced by successive cambia in stems of Avicennia trees is more abundant with increasing soil water salinity and decreasing inundation frequency within the mangrove forest and woody shrub and tree species with this type of secondary phloem mainly occurs in either dry or saline environments (Robert et al., 2011). Hence, we hypothesize that secondary phloem tissue produced by successive cambia allows for increased water storage. Phloem water storage may be advantageous in environmental conditions with variable water availability and frequent drought. Through estimation of the effective water content of woody species with secondary phloem tissue produced by successive cambia, and the variation therein across the stem, we may gain insight into the role of this secondary phloem in the water balance of drought and salt tolerant woody plants, such as Avicennia and Bougainvillea (Knox \& Black, 2000; Knox, 2001; Kobayashi et al., 2007) individuals.

Imaging methods based on nuclear magnetic resonance (NMR), called magnetic resonance imaging (MRI), are among the techniques that allow for direct in vivo observation of water content and water movement in 
plants (Van As et al., 2009). Other methods are heat tracing methods (heat balance, heat pulse or heat dissipation) and radioisotope or stable isotope tracing methods (Calder et al., 1986; Lambs \& Saenger et al., 2011). However, the exceptional aspect of MRI is the possibility for spatially resolved results, allowing for sap flow and water content data on every location of the plant's stem (Van As et al., 2009). In the last decades, NMR flow imaging has become a growing discipline in the study of xylem and phloem sap transport over long and short distances in plants (e.g. Kuchenbrod et al., 1996; Rokitta et al., 1999; Olt et al., 2000; Holbrook et al., 2001; Scheenen et al., 2002; Scheenen et al., 2007; Van As, 2007; Windt, 2007; Kaufmann et al., 2009; Mullendore et al., 2010) with few studies on trees (Kuroda et al., 2006; Windt et al., 2006; Homan et al., 2007; Merela et al., 2009; Umebayashi et al., 2011; De Schepper et al., 2012).

All NMR experiments are based on the interaction between the magnetic moment of certain nuclei, especially ${ }^{1} \mathrm{H}$, and an external magnetic field (Köckenberger, 2001; Van As, 2007). A strong static magnetic field is used to create sample magnetization that is then manipulated by radio frequency (RF) pulses and detected through induction of a weak voltage in a coil placed around the sample (Köckenberger, 2001). The magnetization is measured in the presence of a magnetic gradient, allowing for one-dimensional projection in the direction of the gradient after Fourier transformation of the detected signal as a function of time (Köckenberger, 2001).

It has already been proven that the bark tissues of Quercus robur (De Schepper et al., 2012) and Populus (Windt et al., 2006) trees, $1-2 \mathrm{~cm}$ in stem diameter and 1.1-1.5 $\mathrm{m}$ in height, have the highest water content when compared to the other tissues within the stems of these trees. Also, the non-conductive bark cells in the same Quercus trees were put forward as contributing most to the water storage capacity of the tree stem (De Schepper et al., 2012). If the phloem tissue of the bark has an important role in the water household of plants (Van As et al., 2009) and trees, it is probable that also other living tissues within a tree's stem, especially secondary phloem if present, significantly contribute to the tree's water reserves. It is generally accepted that phloem in plants with a single vascular cambium function for one year only (Raven et al., 1999; Rosner et al., 2001; Carlquist, 2007). For plants with successive cambia, a greater area of conducting phloem area has been proposed, based on the continued production of secondary phloem by the internal vascular cambia (Carlquist, 2007). To our knowledge, physiological experiments providing evidence that secondary phloem tissue in plants with successive cambia is still active are lacking, with the exception of one study by Fahn \& Shchori (1967). Water conduction can take place in more than the outermost stem part of Avicennia trees (Robert \& Schmitz, unpublished data). The question then remains: what about the actual water content of secondary phloem tissue produced by successive cambia, if present, in woody species? Are the secondary phloem cells water-filled over the entire stem? Do they play a role in the axial and radial water transport in tree stems? A positive answer would confirm the ecological advantage that we suggested for species with secondary phloem tissue produced by successive cambia in conditions of physiological drought due to high soil water salinity or water shortage (Robert et al., 2011).

In this study, we used MRI to visualize the stem water content of three species with successive cambia, the mangroves Avicennia marina and A. officinalis and the non-mangrove Bougainvillea spectabilis. We tested the hypothesis that not only the outermost phloem tissue has high water content but also the secondary phloem tissues over the entire stem from the bark inward to the pith, herewith serving as water storage sites. One tree of each species has been selected for the study: a Bougainvillea tree, cultivated in a temperate climate and directly subjected to MRI and two Avicennia trees taken from the mangrove forest, transported and measured, after an acclimatisation period in conditions different from its natural environment. The general approach is viewed as a preliminary and pioneering step to assess an extra line of evidence for the ecological significance of secondary phloem tissue produced by successive cambia.

\section{Materials and Methods \\ Plant material}

A Bougainvillea spectabilis WILLD. plant with a stem of $1.20 \mathrm{~cm}$ in diameter and $c a .80 \mathrm{~cm}$ in height, trimmed when cultivated as a single stemmed small tree, has been obtained from a local plant dealer in Belgium. Two small Avicennia trees have been transported from the mangrove forest of Gazi Bay (Kenya) (Avicennia marina (Forssk.) Vierh. - tree 1) and Leyte island (The Philippines) (Avicennia $c f$. officinalis Linn. - tree 2) to the Wageningen NMR Centre (Wageningen University, The Netherlands) where MRI measurements were conducted. Tree 1 was ca. $150 \mathrm{~cm}$ high and had a stem diameter of $1.25 \mathrm{~cm}$ while tree 2 was $c a .65 \mathrm{~cm}$ high with a stem diameter of $0.8 \mathrm{~cm}$. During transport, the Avicennia trees were covered with insulation material and between arrival and actual MRI measurements there was an acclimatization period of 2.5 months in the mangrove greenhouse of Burger's Zoo in Arnhem (The Netherlands) during which the tree was watered with fresh water (tree 1), and of one week in a climate chamber (air temperature: $22^{\circ} \mathrm{C}$; relative air humidity: $70 \%$ ) during which the tree was watered with saline water (20-30 g/l) (tree 2). While the xylem and phloem 
tissue in Avicennia trees has a reticulate structure (Robert et al., 2011), numerous strands of vascular increments, composed of both xylem vessels and phloem tissue, are scattered over the stem of Bougainvillea (Figure 1).

\section{Magnetic Resonance Imaging (MRI)}

Measurements were done in a $3 \mathrm{~T}$ (Bougainvillea tree and Avicennia tree 1) and a 0.7 T MRI system (Avicennia tree 2) at the Wageningen NMR Centre (Wageningen University, The Netherlands). The 3T
MRI system (Figure 2) consists of an Avance console (Bruker, Karlsruhe, Germany) and a superconducting magnet with a $50 \mathrm{~cm}$ vertical bore (Magnex, Oxford, UK), generating a magnetic field of $3 \mathrm{~T}(128 \mathrm{MHz}$ proton frequency). Measurements were performed in the centre of a gradient coil that was mounted around the stem (Figure 2b-d) and that generates maximum gradient strengths of $1 \mathrm{~T} / \mathrm{m}$. For induction and detection of the signal, a radio frequency (RF) coil, consisting of two half cylinders, was placed around the tree stem at $c a .40 \mathrm{~cm}$ height above the pot surface.
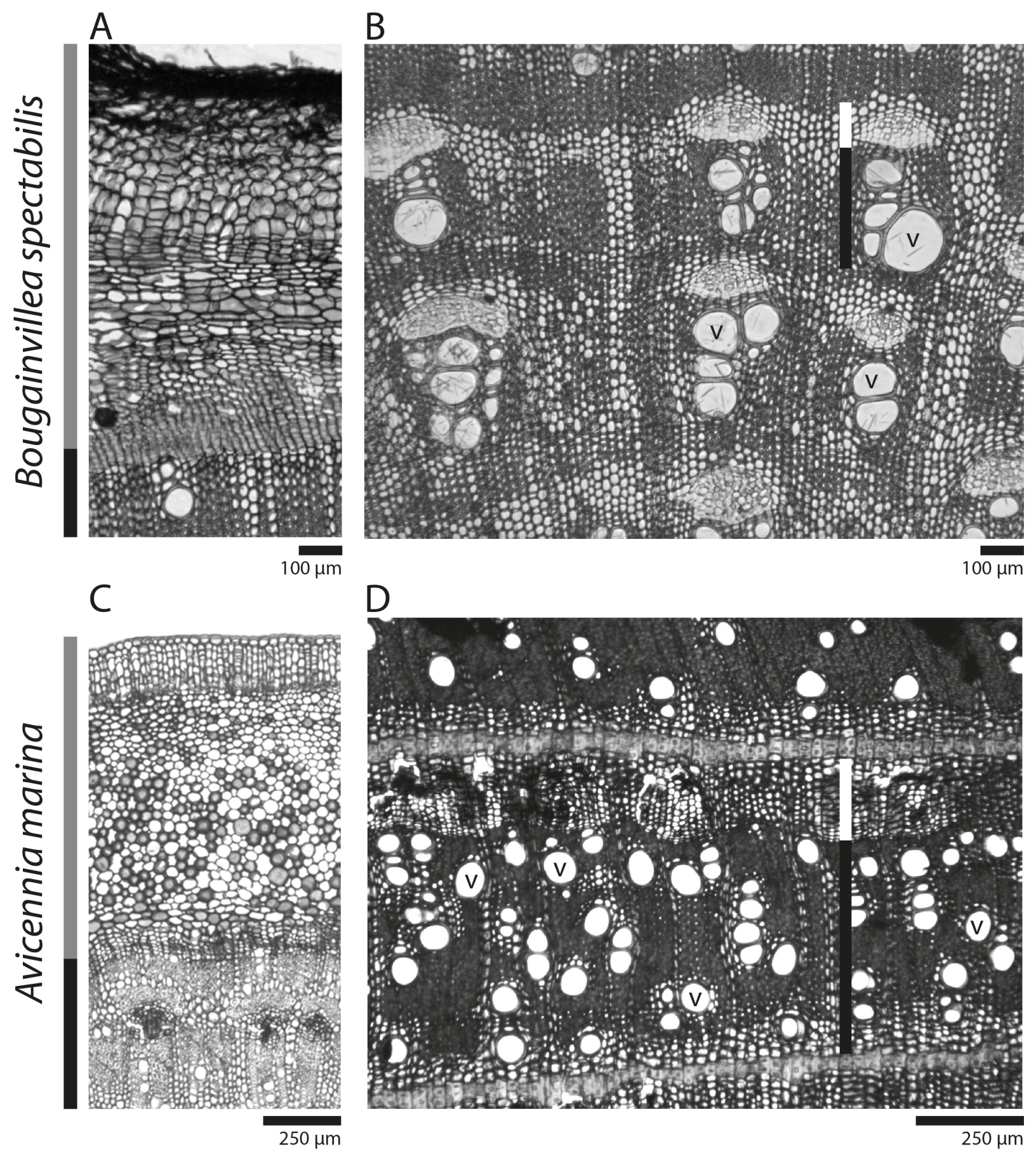

Figure 1: Internal stem anatomy of Bougainvillea spectabilis (A, B) and Avicennia marina (C, D), showing the bark tissue (grey bars) (A, C), the secondary phloem tissue produced by successive cambia (white bars) and the xylem tissue (black bars) with water conducting vessels $(\mathrm{v})(\mathrm{B}, \mathrm{D})$. Stems were sectioned using a sliding microtome after which a picture was taken via a camera connected to a microscope. The stem anatomy of $A$. officinalis is highly similar to the one of $A$. marina. 

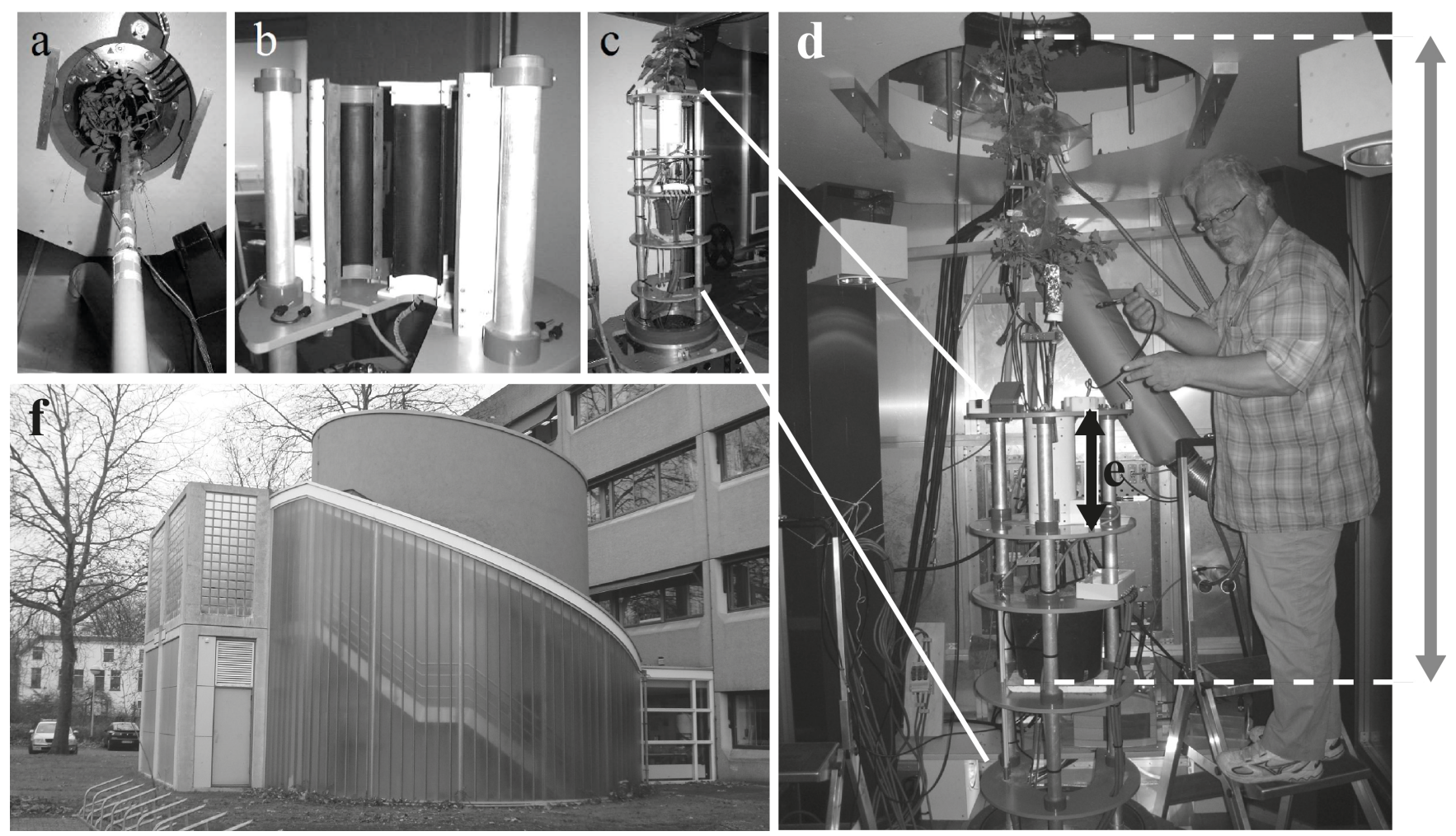

Figure 2: 3 T MRI system at Wageningen University (The Netherlands) showing (a) the lifting of a tree into the superconducting magnet, (b, c, d, e) the gradient coil, (b) open and (c, d, e) placed around a tree, (d) Edo Gerkema preparing an oak tree for MRI analysis in the space under the magnet and (f) the 3T MRI building from outside. The grey arrow indicates the length of a $1.80 \mathrm{~m}$ high tree, from roots to crown top. Figures a, b and c are adapted from Homan et al., 2007. Picture d is taken by Paul Copini.

The 0.7 T MRI system consists of an Avance console and electromagnet (Bruker, Karlsruhe, Germany) with a $10 \mathrm{~cm}$ air gap, generating a magnetic field of $0.7 \mathrm{~T}$ (30 $\mathrm{MHz}$ proton frequency). Maximum gradient strength that can be generated is $1 \mathrm{~T} / \mathrm{m}$. For induction and detection of the NMR signal a solenoid RF coil was constructed by wrapping copper wire around a mould slightly wider than the tree stem. The coil was connected to a tuning circuit and electromagnetically shielded with aluminium foil and copper tape.

For a more detailed description of the MRI systems: see Homan et al. (2007).

During the measurement periods air temperature ranged from $22^{\circ} \mathrm{C}$ to $26^{\circ} \mathrm{C}$. Relative air humidity was $28-40 \%$ (3 T MRI) and 50-65\% (0.7 T MRI). Trees were subjected to a day-night cycle of 12:12 hours and regularly watered with fresh water (Bougainvillea and Avicennia tree 1) and saline water $(20-30 \mathrm{~g} / \mathrm{l})$ (Avicennia tree 2). These conditions were chosen to maximally allow normal functioning of all three plants. The conditions imposed on the Avicennia trees were intended to represent natural conditions with high demand on the water transport system either imposed by very low relative humidity or by the combination of high relative humidity and saline water.

For all quantitative T2 measurements, a multiple spin echo imaging sequence has been used (Edzes et al., 1998). The following settings were applied: field of view: 20 × $20 \mathrm{~mm}$ (Bougainvillea), $18.5 \times 18.5 \mathrm{~mm}$ (Avicennia 1) and 11.4 x 11.4 (Avicennia 1); matrix: 256 x 256; slice thickness: $3 \mathrm{~mm}$; number of averages: 8 (Bougainvillea) and 16 (Avicennia); echo time: 7.19 ms (Bougainvillea and Avicennia 1) and $6.88 \mathrm{~ms}$ (Avicennia 2); number of echos: 96 (Bougainvillea and Avicennia 2) and 64 (Avicennia 1); repetition time: $2500 \mathrm{~ms}$. Differences of values between the trees were to optimise the spatial (field of view) and the signal-tonoise and time resolution (number of averages). They furthermore depend on the longest relevant T2 (number of echoes).

Several quantitative T2 measurements were made, both during day and night after which, measured proton density and $\mathrm{T} 2$ values were visualized over the stem disc through a colour scale from the smallest (black) to the largest (white) value. Proton density is a measure of the water content, while T2 is a time constant related to transverse relaxation after magnetization and radio frequency pulsing of a sample (Köckenberger, 2001; Van As 2007). T2 values change with the size of the measured compartment (van der Weerdt et al., 2001, Van As, 2007) and are as such an indication of the tissue type in plants. No differences could be observed in water content and T2 patterns between the different measurements, neither in Avicennia, nor in Bougainvillea. 


\section{Proton density (a.u.)}
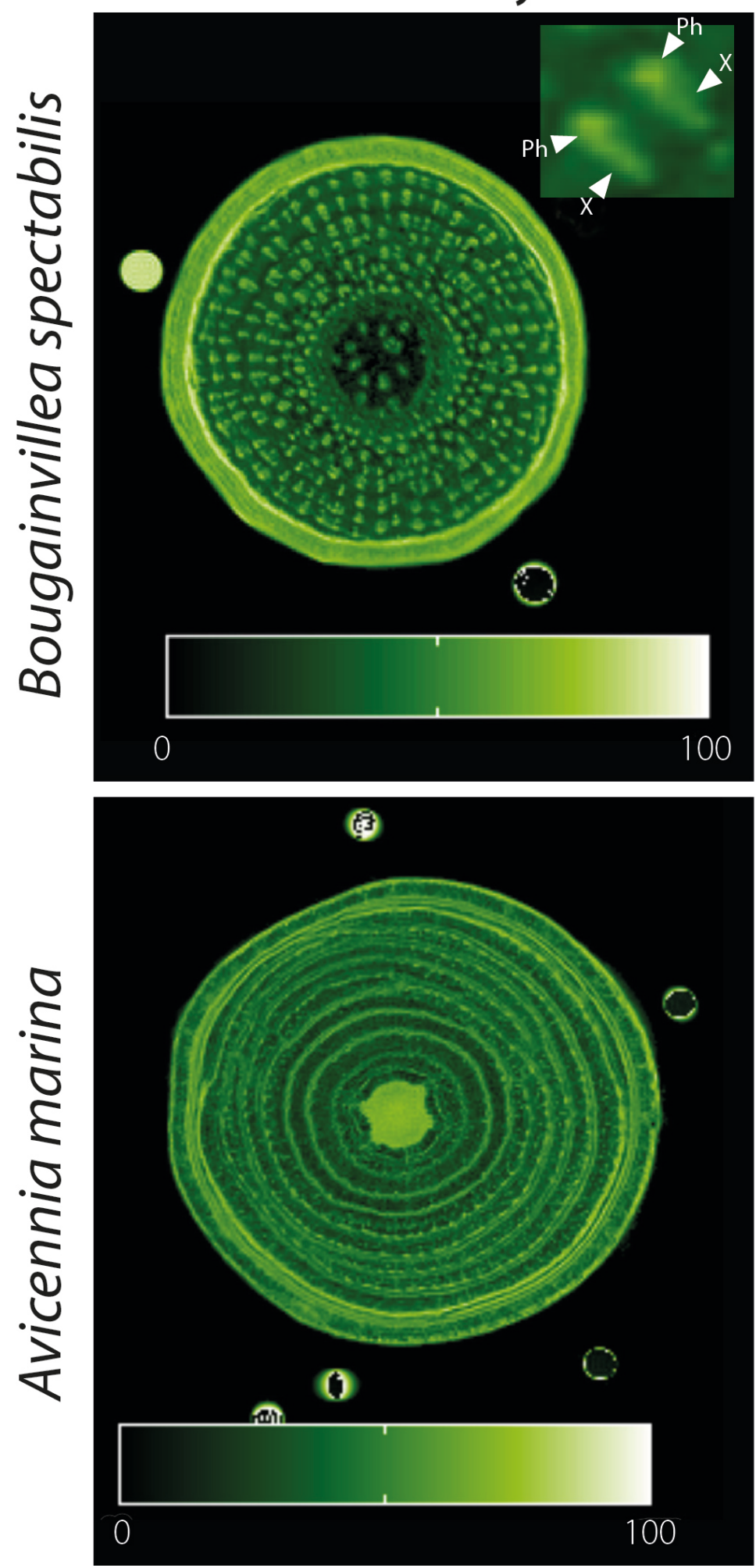

T2 (ms)
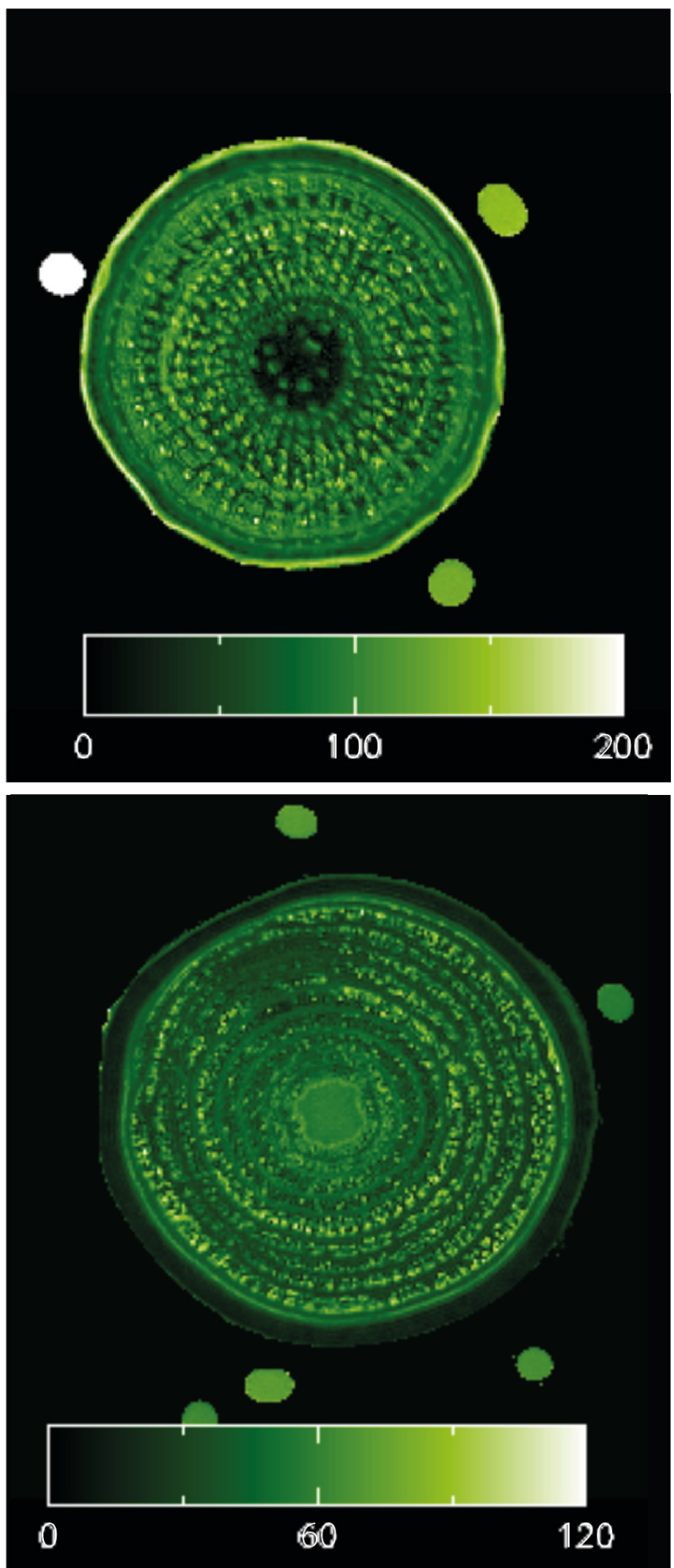

Figure 3: Proton density (water content) on a gradient from 0 (black - low water content) to 100 (white - high water content) and T2 images of intact Bougainvillea spectabilis and Avicennia marina stems obtained through magnetic resonance imaging (MRI). The stem diameters are $1.20 \mathrm{~cm}$ and $1.25 \mathrm{~cm}$ for the Bougainvillea and Avicennia plant, respectively. The inset in the upper left panel is a zoom of two vascular strands, composed of phloem $(\mathrm{Ph})$ and xylem (X) cells (Figure 1). Proton density is in arbitrary units (a.u.). Only proton density directly links to water content. T2 values represent the relaxation time after magnetisation and radio frequency pulsing and are strongly influenced by the degree of mobility of the protons and their physico-chemical environment with higher values for more mobile and lower values for less mobile protons. T2 values are as such also a measure of cell size/type. 


\section{Results and discussion}

Amplitude images showed the water content of the different tissues over the entire stem of both Bougainvillea and Avicennia trees (Figure 3). The bark and the vascular bundles of Bougainvillea had high water content but the highest amount of water could be observed in the zone of the outermost vascular cambium (up to the first lignified xylem cells). This is in agreement with observations in Quercus (Kuroda et al., 2006; De Schepper et al., 2012), Populus (Windt et al., 2006) and Pinus (Umebayashi et al., 2011) tree stems. High water content is expected in the cambial zone since water is crucial in cell formation and especially cell enlargement (Woodward, 2004; Arend et al., 2007). When looking in more detail to the water content of the vascular bundles of Bougainvillea, we see that in the outermost zone of many bundles, the water content was higher than in the innermost zone, visible by the lighter yellow-green and the slightly darker green colour respectively (Figure 3 - inset in above left panel). Since each vascular bundle in this species is composed of phloem on the outside and xylem on the inside (Figure 1), the higher water content was situated in the phloem tissue. The phloem cells in Bougainvillea stems are thus full of water, supporting their role in water storage and supply.

In Avicennia, amplitude images showed higher water content in the pith and in the outermost zone of the studied stems (Figure 3; tree 2: data not shown), although this was less pronounced than in the studied Bougainvillea tree. The phloem bands in both studied Avicennia trees had relatively high water content throughout the entire stem, despite the different treatments they got (tree 1: fresh water and low relative humidity versus tree 2 : saline water and higher relative humidity). The considerable amount of water in the secondary phloem tissue of both Avicennia and Bougainvillea throughout the entire stem strengthens the importance attributed to the secondary phloem tissue in the water household of trees with successive cambia and other cambial variants. The presence of water storage tissues evenly distributed over the tree stem could indeed be responsible for their ecological advantage in conditions of water shortage as has been proposed earlier (Robert et al., 2011).

T2 values are not radially homogeneous in the studied $B$. spectabilis and A. marina stems, which is indicated by the presence or absence of light green dots on the T2 images (Figure 3 - right panels) often in concentric zones. Since T2 values scale with compartment size (van der Weerdt et al., 2001; Van As, 2007), narrower vessels in some zones of the stems could possibly be at the basis of lower T2 values in these zones. However, to obtain further understanding of the physiology in terms of hydraulic function behind the observed patterns, sap flow measurements should be conducted.

\section{Conclusion}

We can conclude that the secondary phloem tissue produced by successive cambia of both Bougainvillea and Avicennia has high water content. This strengthens the contribution of this secondary phloem tissue to ecological success in conditions of physiological drought caused by water shortage or high soil water salinity that we proposed earlier (Robert et al., 2011). In this study we could only address young trees with narrow diameter. Further research should address the water content of the secondary phloem at the interior part of large trees with successive cambia in relation to the functionality of the xylem vessels.

Our MRI results on Bougainvillea and Avicennia are preliminary and only a very few trees have been measured, yet we consider them significant. The nondestructive and real-time study of phloem transport and water exchange between the xylem and the phloem tissue in mature trees in the field is difficult (Sevanto et al., 2011). The study of secondary (not bark) phloem tissue in trees presents additional complications. However, further studies of the functioning of secondary phloem tissue produced by successive cambia and its role in the water household of plants could offer important insight in understanding the survival and thriving of plants under physiological drought and the functioning of trees in general. Combining techniques and new approaches may overcome the current difficulties and should therefore be continued. Studies on drought and/or salt tolerant woody plants combining MRI and dendrometer measurements (De Schepper et al., 2012), using portable NMR devices (Windt et al., 2011) or specifically addressing the coupling between xylem and phloem through dendrometer analysis (Sevanto et al., 2011) and NMR measurements of radial transport and (radial) tissue permeability (Sibgatullin et al., 2010) could be a first possible continuation. The specific effect of different treatments, e.g. watering with fresh water versus salty water, should also be addressed in long-term experimental set-ups or by comparing several trees from contrasting locations.

\section{Acknowledgements}

We are grateful to Hamisi Ali Kirauni and James Gitundu Kairo of the Kenya Marine and Fisheries Research Institute (KMFRI, Mombasa, Kenya), to Mohamed Omar Said Mohamed of Kenya Wildlife Service and to Hilde Robert and Mia Van Mellaert for their help and support in the transport of the Avicennia marina tree; to Joep Wensing and Ernst Kamphuis of Burger's Zoo (Arnhem, The Netherlands) for housing the Avicennia plants in the mangrove greenhouse of Burger's Zoo; to Arie van Hoek and John Philippi of the Wageningen NMR Centre (Wageningen University, The Netherlands) for their assistance during scanning and scanning preparation and to Hilde 
Robert for her assistance in making thin-sections. The research was financial supported by the Agency for Innovation by Science and Technology (IWT, Flanders, Belgium), the Research Foundation Flanders (FWO, Flanders, Belgium), the Company of Biologists (COB) through the Society for Experimental Biology (SEB), the European Cooperation in Science and Technology (COST) on the Terrestrial Biosphere in the Earth System (TERRABITES) via a Short Term Scientific Mission and the "Stichting ter bevordering van wetenschappelijk onderzoek in Afrika" (SBWOA, Belgium). This work has been carried out under the framework of the project 'CREC' (EU IRSES \#247514) and the COST FP1106 network STReESS.

\section{References}

Arend M \& Fromm J (2007) Seasonal change in the drought response of wood cell development in poplar. Tree Physiology 27: 985-992.

Calder IR, Narayanswamy MN, Srinivasalu NV, Darling WG \& Lardner AJ (1986) Investigation into the use of deuterium as a tracer for measuring transpiration from Eucalypts. Journal of Hydrology 84: 345-351.

Carlquist S (2007) Successive cambia revisited: ontogeny, histology, diversity, and functional significance. Journal of the Torrey Botanical Society 134: 301-332.

De Schepper V, van Dusschoten D, Copini P, Jahnke S \& Steppe K (2012) MRI links stem water content to stem diameter variations in transpiring trees. Journal of Experimental Botany 63: 2645-2653.

Edzes HT, van Dusschoten D \& Van As H (1998) Quantitative T2 imaging of plant tissues by means of multiecho MRI microscopy. Magnetic Resonance Imaging 16: 185-196.

Fahn A (1985) The development of the secondary body in plants with interxylary phloem. In: Kucera, L, J ed(s). Xylorama . Birkhauser Verlag: Basel, pp. 58-67.

Fahn A \& Shchori Y (1967) The organization of secondary conducting tissues in some species of the Chenopodiaceae. Phytomorphology 17: 147-154.

Holbrook NM, Ahrens ET, Burns MJ \& Zwieniecki MA (2001) In vivo observation of cavitation and embolism repair using magnetic resonance imaging. Plant Physiology 126: 27-31.

Homan NM, Windt CW, Vergeldt FJ, Gerkema E \& Van As H (2007) 0.7 and 3 T MRI and sap flow in intact trees: xylem and phloem in action. Applied Magnetic Resonance 32: 157-170.

Kaufmann I, Schulze-Till T, Schneider HU, Zimmermann U, Jakob P \& Wegner LH (2009) Functional repair of embolized vessels in maize roots after temporal drought stress, as demonstrated by magnetic resonance imaging. New Phytologist 184: 245-256.

Kobayashi KD, McConnell \& Griffis J (2007) Bougainvillea. Ornamentals and Flowers: Oct. $2007-$ OF-38. Published by the College of Tropical Agriculture and Human Resources (CTAHR). http://www.ctahr.hawaii.edu/freepubs

Köckenberger W (2001) Functional imaging of plants by magnetic resonance experiments. Trends in Plant Science 6: 286-292.
Knox GW \& Black RJ (2000) Salt Tolerance of Landscape Plants for South Florida. Series of the Department of Environmental Horticulture, Florida Cooperative Extension Service, Institute of Food and Agricultural Sciences, University of Florida, USA: ENH-145. http://edis.ifas.ufl.edu.

Knox GW (2001) Drought Tolerant Plants for North and Central Florida. Series of the Department of Environmental Horticulture, Florida Cooperative Extension Service, Institute of Food and Agricultural Sciences, University of Florida, USA: CIR807. http://edis.ifas.ufl.edu.

Kuchenbrod E, Landeck M, Thurmer F, Haase A \& Zimmermann U (1996) Measurement of water flow in the xylem vessels of intact maize plants using flowsensitive NMR imaging. Botanica Acta 109: 184-186.

Kuroda K, Kanbara Y, Inoue T \& Ogawa A (2006) Magnetic resonance micro-imaging of xylem sap distribution and necrotic lesions in tree stems. IAWA Journal 27: 3-17.

Lambs L \& Saenger A (2011) Sap flow measurements of Ceriops tagal and Rhizophora mucronata mangrove trees by deuterium tracing and lysimetry. Rapid Communications in Mass Spectrometry 25: 2741-2748.

Merela M, Oven P, Sersa I \& Mikac U (2009) A single point NMR method for an instantaneous determination of the moisture content of wood. Holzforschung 63: 348-351.

Mullendore DL, Windt CW, Van As H \& Knoblauch M (2010) Sieve tube geometry in relation to phloem flow. Plant Cell 22: 579-593.

Olt S, Krotz E, Komor E, Rokitta M \& Haase A (2000) Na23 and H-1 NMR micro-imaging of intact plants. Journal of Magnetic Resonance 144: 297-304.

Raven P, Evert R \& Eichhorn S (1999) Biology of plants. New York, Worth Publishes.

Robert EMR, Schmitz N, Boeren I, Driessens T, Herremans K, De Mey J, Van de Casteele E, Beeckman H \& Koedam N (2011) Successive cambia: a developmental oddity or an adaptive structure? Plos One 6: e16558.

Rosner S, Baier P \& Kikuta SB (2001) Osmotic potential of Norway spruce (Picea abies (L.) Karst.) secondary phloem in relation to anatomy. Trees - Structure and Function 15: 472-482.

Rokitta M, Peuke AD, Zimmermann U \& Haase A (1999) Dynamic studies of phloem and xylem flow in fully differentiated plants by fast nuclear-magnetic-resonance microimaging. Protoplasma 209: 126-131.

Scheenen T, Heemskerk A, de Jager A, Vergeldt F \& Van As H (2002) Functional imaging of plants: a nuclear magnetic resonance study of a cucumber plant. Biophysical Journal 82: 481-492.

Scheenen TWJ, Vergeldt FJ, Heemskerk AM \& Van As H (2007) Intact plant magnetic resonance imaging to study dynamics in long-distance sap flow and flow-conducting surface area. Plant Physiology 144: 1157-1165.

Sevanto S, Holtta T \& Holbrook NM (2011) Effects of the hydraulic coupling between xylem and phloem on diurnal phloem diameter variation. Plant Cell and Environment 34: 690-703.

Sibgatullin TA, Vergeldt FJ, Gerkema E \& Van As H (2010) Quantitative permeability imaging of plant tissues. European Biophysics Journal 39: 699-710.

Umebayashi T, Fukuda K, Haishi T, Sotooka R, Zuhair S \& 
Otsuki K (2011) The developmental process of xylem embolisms in pine wilt disease monitored by Multipoint Imaging using Compact Magnetic Resonance Imaging. Plant Physiology 156: 943-951.

Van As H (2007) Intact plant MRI for the study of cell water relations, membrane permeability, cell-to-cell and longdistance water transport. Journal of Experimental Botany 58: 743-756.

Van As H, Scheenen T \& Vergeldt FJ (2009) MRI of intact plants. Photosythesis Research 102: 213-222.

van der Weerd L, Claessens M, Ruttink T, Vergeldt FJ, Schaafsma TJ \& Van As H (2001) Quantitative NMR microscopy of osmotic stress responses in maize and pearl millet. Journal of Experimental Botany 52: 23332343.

Wheeler EA, Baas P, Gasson PE (1989) IAWA list of microscopic features for hardwood identification. IAWA Bulletin n.s. 10: 219-332

Windt CW, Vergeldt FJ, De Jager PA \& Van As H (2006) MRI of long-distance water transport: a comparison of the phloem and xylem flow characteristics and dynamics in poplar, castor bean, tomato and tobacco. Plant Cell and Environment 29: 1715-1729.

Windt CW (2007) Nuclear magnetic resonance imaging of sap flow in plants. Wageningen, Wageningen University. PhD thesis, ISBN 978-90-8504-729-2.

Windt CW, Soltner H, van Dusschoten D \& Bluemler P (2011) A portable Halbach magnet that can be opened and closed without force: the NMR-CUFF. Journal of Magnetic Resonance 208: 27-33.

Woodward I (2004) Plant science: tall storeys. Nature 428: 807-808. 